\title{
3D nonlinear photolithography of tin oxide ceramics via femtosecond laser
}

\author{
Nianyao Chai ${ }^{1,2 \dagger}$, Yanan Liu $^{3 \dagger}$, Yunfan Yue ${ }^{1}$, Ping Wei ${ }^{1}$, Xuewen Wang ${ }^{1,2^{*}}$, Junjie Zhao ${ }^{1}$, Qi Zhang ${ }^{1}$, \\ Fuzhi Huang ${ }^{1}$, Zhongle Zeng ${ }^{1}$, Zongsong Gan ${ }^{3 *}$, Liqiang $\mathrm{Mai}^{1,2^{*}}$ and Yibing Cheng ${ }^{1,2}$
}

\begin{abstract}
As a wide band gap semiconductor material, tin oxide $\left(\mathrm{SnO}_{2}\right)$ has been widely used in gas sensing, optoelectronics and catalysis. The complex micro and nanoscale threedimensional (3D) geometric structures endow the conventional $\mathrm{SnO}_{2}$ ceramics with novel properties and functionalities. Nevertheless, ceramics cannot be cast or machined easily due to their high mechanical toughness and resistance. The additive manufacturing opens a great opportunity for flexibly geometrical shaping, while the arbitrary shaping of $\mathrm{SnO}_{2}$ ceramics at micro and nanoscale is always a challenge. Herein, preceramic monomers which can be polymerized under ultrafast laser irradiation, were utilized to form complex and arbitrary $3 \mathrm{D}$ preceramic polymer structures. After calcination treatment, these green-body structures could be converted into pure high-dense $\mathrm{SnO}_{2}$ ceramics with uniform shrinkage, and the feature size was down to submicron. Transmission electron microscopy (TEM) analysis displays that the printed $\mathrm{SnO}_{2}$ ceramic nanostructures can be nanocrystallized with grain sizes of $2.5 \pm 0.4 \mathrm{~nm}$. This work provides the possibility of manufacturing 3D $\mathrm{SnO}_{2}$ ceramic nanostructures arbitrarily with sub-100 $\mathrm{nm}$ resolution, thus making it promising for the applications of $\mathrm{SnO}_{2}$ in different fields.
\end{abstract}

Keywords: tin oxide ceramics, nonlinear photolithography, femtosecond laser

\section{INTRODUCTION}

Metal oxides have been intensively employed in sensors, optoelectronics and catalysis devices for their excellent electronic and chemical properties [1-3]. Structuring metal oxides down to micro and nanoscale enables the exotic properties. For example, the conductivity and the performance of gas sensors can be tailored via threedimensional (3D) stacking metal oxide nanowires [3], and crumpling metal oxides nanosheets [4], respectively. And the photocatalytic performance can be highly enhanced via dehiscent mesoporous titanium oxide $\left(\mathrm{TiO}_{2}\right)$ microspheres [5]. As typical $1 \mathrm{D}$ or $2 \mathrm{D}$ nanomaterials, nanowires and thin films are known to possess exceptional properties. However, their size-dependent properties would disappear when they are scaled up. Their overall performances could also be weakened by the interfaces when they are clustered in a composite in particular [6]. In order to overcome the dilemma, highly ordered 3D nanostructured materials are indispensable. Combining 3D-ordered nanostructures with multi-physical interaction, unnatural properties have been designed for various applications [7-10]. Compared with metals and polymers, constructing metal oxides into complex nanostructures arbitrarily is more difficult due to their extremely high melting point [11-13]. In addition, the conventional 3D printing technologies based on powderbased layer-by-layer processes would cause unavoidable limited resolution and residual porosity, thus leading to a decrease in strength [14-18]. Therefore, the technology that can prepare arbitrary $3 \mathrm{D}$ metal oxide nanostructures with high resolution and high density is highly desired.

Recently, two-photon polymerization induced by nonlinear absorption via femtosecond pulses has been proved to be a high-resolution 3D printing technique [19]. Various 3D geometrical nanostructures fabricated through this technique have been demonstrated [20-22]. By using photosensitive $\mathrm{TiO}_{2}$ resist, the complex $3 \mathrm{D}$ nanostructures were patterned by femtosecond laser direct

\footnotetext{
${ }^{1}$ State Key Laboratory of Advanced Technology for Materials Synthesis and Processing, International School of Materials Science and Engineering, Wuhan University of Technology, Wuhan 430070, China

${ }^{2}$ Foshan Xianhu Laboratory of the Advanced Energy Science and Technology, Guangdong Laboratory, Foshan 528216, China

${ }^{3}$ Wuhan National Laboratory for Optoelectronics, Huazhong University of Science and Technology, Wuhan 430074, China

${ }^{\dagger}$ These authors contributed equally to this work.

* Corresponding authors (emails: xwwang@whut.edu.cn (Wang X); ganzongsong@hust.edu.cn (Gan Z); mlq518@whut.edu.cn (Mai L))
} 
writing, which provided a novel way to structure $3 \mathrm{D}$ ceramic materials [23]. Followed by calcination, 3D-architected zinc oxide ceramics were fabricated by femtosecond laser direct writing [24]. Furthermore, by controlling the shrinkage, sub-100 nm of structural feature size was achieved while keeping the 3D geometry $[25,26]$.

As a semiconductor material with a band gap of $3.6 \mathrm{eV}$, $\mathrm{SnO}_{2}$ has been widely used in sensors, electrodes and catalysis [27-29]. In this work, a high-resolution approach to manufacture arbitrary $3 \mathrm{D}$ nanostructured $\mathrm{SnO}_{2}$ ceramics was proposed. A simple tin-containing photoresist for two-photon lithography (TPL) was prepared. By adjusting the tin content of the photoresist, the twophoton polymerization threshold could be tailored. The exposure dose was changed by tuning the laser scanning velocity and the effective intensity. Various feature sizes of $\mathrm{SnO}_{2}$ preceramic structures from $400 \mathrm{~nm}$ to $2.3 \mu \mathrm{m}$ were fabricated under loose focusing condition with a numerical aperture (NA) of 0.26. After demonstrating this technique, an oil immersion objective lens with an NA of 1.3 was used to fabricate complex $3 \mathrm{D}$ microstructures. The preceramic structures were calcined with well controlled shrinkage whereby the feature sizes ranging from sub-100 $\mathrm{nm}$ to $400 \mathrm{~nm}$ were achieved. The calcination process was optimized through simultaneous thermal analysis (STA). The calcined structures were characterized by X-ray diffraction (XRD) and Fourier transform infrared (FTIR). High-resolution transmission electron microscopy (HRTEM) analysis reveals that the calcined $\mathrm{SnO}_{2}$ was fully dense and nanocrystallized, with an average grain size around $2.5 \pm 0.4 \mathrm{~nm}$. These findings demonstrated a promising way to fabricate complex and arbitrary $3 \mathrm{D}$ nanostructured $\mathrm{SnO}_{2}$ ceramics.

\section{EXPERIMENTAL SECTION}

\section{Preparation of tin-containing photoresist}

In Fig. 1a, stannic chloride hydrated $\left(\mathrm{SnCl}_{4} \cdot 5 \mathrm{H}_{2} \mathrm{O}\right)$ was dissolved in poly(ethylene glycol) diacrylate (PEGDA) with $1 \mathrm{wt} \%$ 2,2-dimethoxy-2-phenylacetophenone (DMPA). A total of $200 \mu \mathrm{L}$ deionized water was added to help $\mathrm{SnCl}_{4} \cdot 5 \mathrm{H}_{2} \mathrm{O}$ and DMPA to dissolve in PEGDA better. The mixture was magnetically stirred at $60^{\circ} \mathrm{C}$ for $4 \mathrm{~h}$.

\section{Ultrafast laser 3D nonlinear photolithography and calcination}

Tin-containing photoresist was drop-casted on the silicon chip and covered with a glass slide. The glass slide was separated from the silicon chip with kapton tapes. A homebuilt TPL system was used for two-photon polymerization (Fig. 1b). A femtosecond laser (Pharos-10 W, light conversion) with a center wavelength of $515 \mathrm{~nm}$ and pulse duration around $260 \mathrm{fs}$ was installed, and a threeaxis positioning stage with galvometer scanning system (ES112166, Aerotech Inc., USA) was integrated. An attenuator (2-EWP-R-0515-M, Altechna) was placed in the optical path to adjust the effective laser intensity. A $10 \times$ objective lens (NA = 0.26) (M Plan Apo NIR, Mitutoyo Corporation) was applied to investigate the two-photon polymerization process via fabricating $3 \mathrm{D}$ microbridges (a nanorod suspended between two piers), and a $100 \times$ oil immersion objective lens ( $\mathrm{NA}=1.3$ ) was used to fabricate the complex $3 \mathrm{D}$ nanostructures. To measure the laser power, a photodiode power meter was used (S120VC, Thorlabs). After the polymerization, samples were first developed in acetone for $5 \mathrm{~min}$, and then immersed in ethanol for $5 \mathrm{~min}$, followed by drying at $60^{\circ} \mathrm{C}$ for $5 \mathrm{~min}$. After development, the samples were calcined in a muffle furnace at ambient pressure in air. The entire process is schematized in Fig. 1c.

\section{Characterization}

To investigate the composition, thermal property and phase during sintering, the samples were prepared with an ultraviolet (UV) curing lamp for $30 \mathrm{~min}$. The FTIR spectra were measured at room temperature with wave number of $4000-400 \mathrm{~cm}^{-1}$ (VERTEX80V, Bruker). Thermogravimetric (TG) analysis, derivative thermogravimetric (DTG) analysis and differential scanning calorimetry (DSC) were carried out with a simultaneous thermal analyzer (STA449F3, Netzsch). The XRD patterns were measured with a powder XRD (PAN alyticalEmpyrean) using a $\mathrm{Cu} \mathrm{Ka}$ radiation. Scanning electron microscopy (SEM) (ProX, Phenom) and TEM (Titan Cubed Themis G2 300, Thermo Fisher) were used to investigate the morphology and the crystalline structure of the microstructure fabricated by TPL after calcination.

\section{RESULTS AND DISCUSSION}

\section{Photolithography process}

The polymerization reactions only occur at the region where the exposure dose reaches the critical value, which is the polymerization threshold. Otherwise, the polymerization reactions would not be initiated and propagated [30]. By varying the scanning velocity and laser effective intensity, the exposure dose for polymerization can be tuned. Different sizes of suspended preceramic 3D microbridge nanostructures were fabricated via tuning 

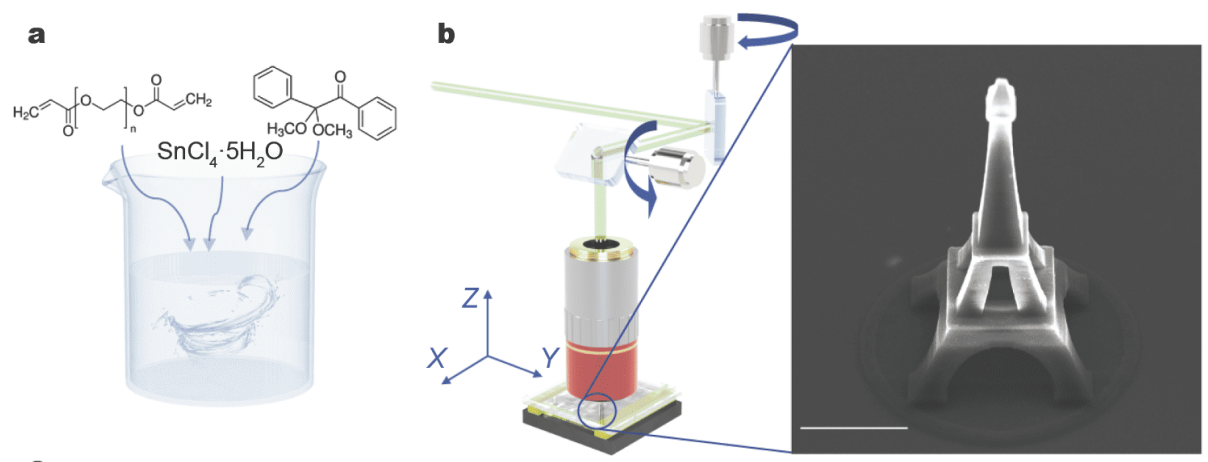

C

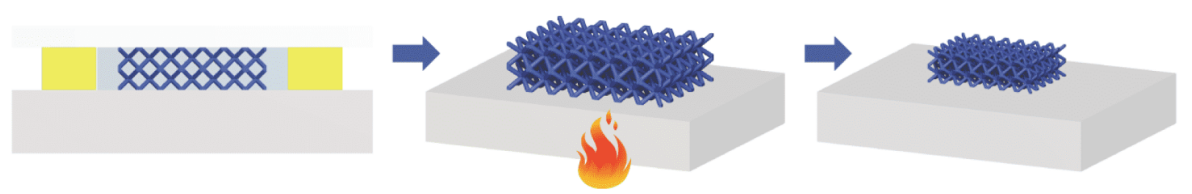

Figure 1 Schematic diagram of $3 \mathrm{D}$ nanostructuring approach of $\mathrm{SnO}_{2}$ ceramics. (a) Preparation process of the tin-containing photoresist. (b) Preparation process of $3 \mathrm{D}$ structures with oil immersion objective lens. The inset is the SEM image of a tower made via the tin-containing photoresist. Scale bar: $20 \mu \mathrm{m}$. (c) The developing and sintering process of the $3 \mathrm{D}$ structures.

the polymerization threshold and exposure dose. The intensity distribution of a Gaussian laser beam in TPL can be described as

$I^{2}=I_{0}^{2} \exp \left(-4 r^{2} / r_{0}^{2}\right)$,

where $I_{0}$ is the laser effective intensity at the center of the focal spot, $r$ and $r_{0}=0.61 \lambda / \mathrm{NA}$ ( $\lambda$ is the laser wavelength) are the radical coordinate and the diffraction-limited spot radii, respectively. Compared with the linear absorption in single photon polymerization, the absorption is proportional to the square of light intensity in TPL, leading to the smaller polymerized region as shown in Fig. 2a (the green and blue curves). By reducing the $I_{0}$ (the blue, brown, and red curves), the feature size of polymerized voxel can be controlled (Fig. 2a). By tuning the concentration of $\mathrm{SnCl}_{4} \cdot 5 \mathrm{H}_{2} \mathrm{O}$, the polymerization threshold and the density of photoresist (Fig. 2b) can be tailored, which introduces an additional freedom to control the fabrication resolution before and after calcination.

Theoretically, the linewidth of the resolution of TPL is affected by the polymerization threshold, laser exposure dose and other laser parameters, which can be described as $[31,32]$

$d=r_{0}\left[\ln \left(\frac{\sigma_{2} N_{0}^{2} n \tau_{L}}{C}\right)\right]^{1 / 2}$,

where $\sigma_{2}$ refers to the effective two-photon absorption cross section, $n$ stands for the number of pulses which equals to $2 r_{0} f / v$ ( $f$ is the pulse repetition rate, $v$ means the scanning velocity), and $\tau_{L}$ is the pulse duration and $C$ is an integration constant. $N_{0}$ is the photon flux intensity which equals to $2 P /\left(\pi r_{0}^{2} \tau_{L} f \hbar \omega_{L}\right)$, where $P$ indicates the laser effective intensity. By substituting the specific expression of $n$ and $N_{0}$ in Equation (2), the estimated linewidth can be obtained:

$d=r_{0}\left[\ln \left(\frac{4 \sigma_{2} P^{2}}{C \pi^{2} r_{0}^{3} \tau_{I} f \hbar^{2} \omega_{L}^{2} v}\right)\right]^{1 / 2}$.

The relationship between $d$ and $P$ can be further simplified as Equation (4):

$d=A\left[\ln \left(B P^{2}\right)\right]^{1 / 2}$,

and the relationship between $d$ and $v$ can be further simplified as Equation (5):

$d=A^{\prime}\left[\ln \left(\frac{D}{v}\right)\right]^{1 / 2}$.

By tuning the laser power and the velocity, the diameters of the fabricated structures in different tin-containing photoresists were measured. The experimental data were fitted according to Equations (4) and (5). The corresponding fitting curves are illustrated in Fig. $2 c, d$ with the dash lines. The values of parameters $A$ and $A^{\prime}$ are close to $1.208 \mu \mathrm{m}$, which are the theoretical value of the diffraction-limited spot radius with the laser wavelength of $515 \mathrm{~nm}$ and NA of 0.26 , as shown in Fig. 2a. By reducing the content of $\mathrm{SnCl}_{4} \cdot 5 \mathrm{H}_{2} \mathrm{O}$ in the photoresist, the values of unknown parameters $B$ and $D$ decrease ac- 

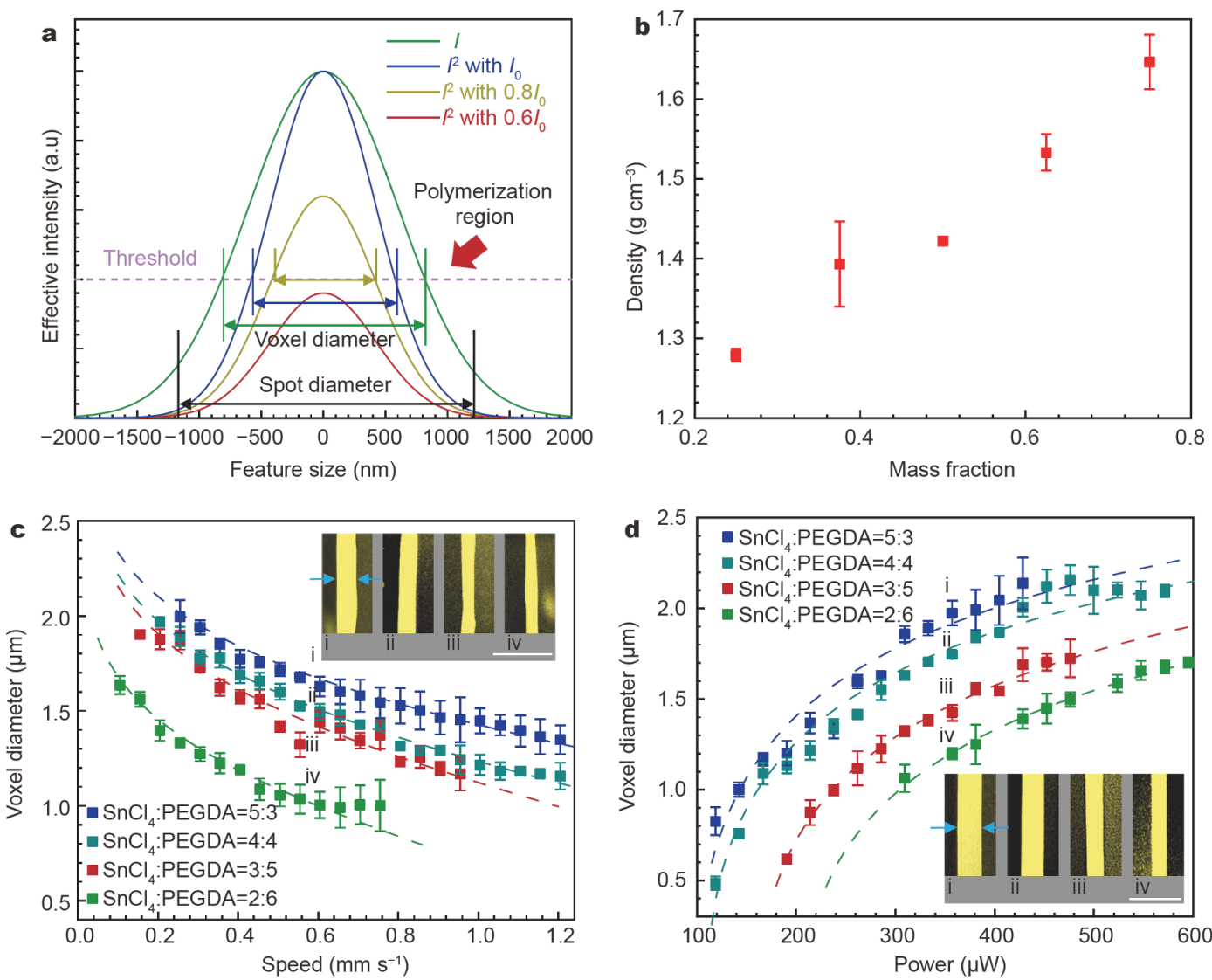

Figure 2 (a) Achievement of sub-diffraction-limit resolution. The feature size is controlled by adjusting the laser intensity $I_{0}$. (b) The relationship of the photoresist density and the mass fraction of $\mathrm{SnCl}_{4} \cdot 5 \mathrm{H}_{2} \mathrm{O}$. (c, d) The sizes of the fabricated structures with different scanning velocities and effective intensities. The insets are SEM images of the nanorods marked in yellow. Scale bars are $5 \mu \mathrm{m}$.

Table 1 The $A, B, A^{\prime}, D$ values of different tin contents processed with different laser powers and scanning velocities ${ }^{\mathrm{a}}$

\begin{tabular}{ccccc}
\hline & \multicolumn{3}{c}{ SnCl $_{4}$ : PEGDA } \\
\cline { 2 - 5 } & $5: 3$ & $4: 4$ & $3: 5$ & $2: 6$ \\
\hline$A$ & 1.21028 & 1.17372 & 1.18875 & 1.18538 \\
$B$ & $9.65231 \times 10^{-5}$ & $7.93994 \times 10^{-5}$ & $3.61204 \times 10^{-5}$ & $2.20081 \times 10^{-5}$ \\
$A^{\prime}$ & 1.21726 & 1.21378 & 1.21223 & 1.01048 \\
$D$ & 3.94847 & 2.81311 & 2.35697 & 1.59638 \\
\hline
\end{tabular}

a) $A$ and $A^{\prime}$ : fitted values of $r_{0}$ in Equations (4) and (5); $B$ and $D$ : constants related to $\sigma_{2}$.

cordingly. This phenomenon can be explained by decreasing $\sigma_{2}$ because the relative concentration of DMPA to PEGDA is reduced. In general, the accuracy of the structure can be controlled by adjusting the laser power, scanning velocity and the concentration of $\mathrm{SnCl}_{4} \cdot 5 \mathrm{H}_{2} \mathrm{O}$.

\section{Sintering process}

The STA results of tin-containing polymer are shown in Fig. 3a. The sample rapidly loses about $54 \%$ of its mass from 140 to $260^{\circ} \mathrm{C}$ with no significant thermal effect, and there is no obvious peak in the XRD pattern (Fig. 3b). This process is caused by the slow evaporation of the solution moisture and the carbonization of the organic matter. At the same time, the intensity of characteristic peaks of the polymer in FTIR spectra decreases above $260^{\circ} \mathrm{C}$ (Fig. 3c), indicating the polymer decomposition and carbonization occur. Between 500 and $600^{\circ} \mathrm{C}$, there is another stage of rapid mass reduction in the TG curve, 

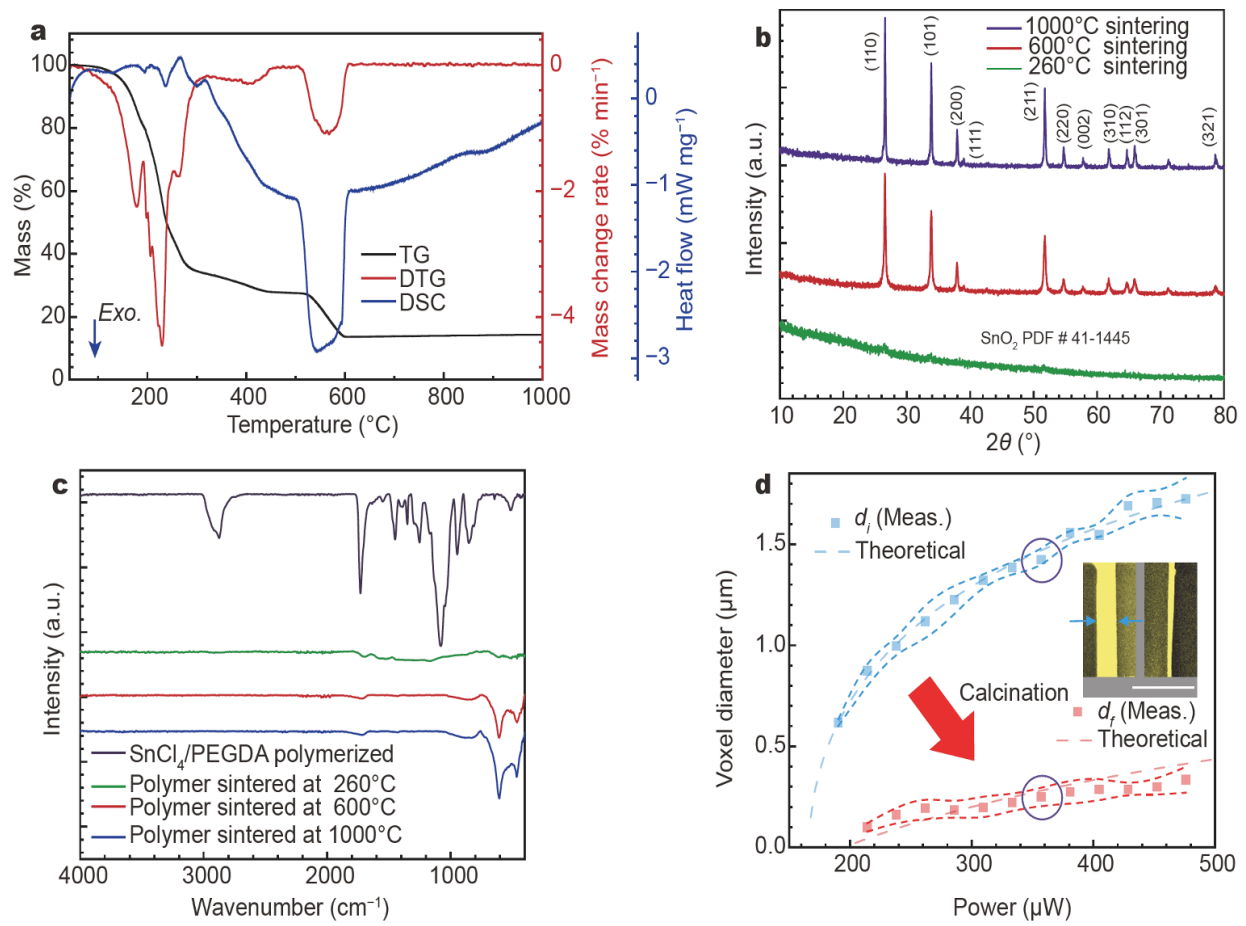

Figure 3 (a) STA results containing TG, DTG and DSC. (b, c) XRD and FTIR characterizations of UV-cured samples. The $\mathrm{SnCl}_{4} \cdot 5 \mathrm{H}_{2} \mathrm{O}$ content of the above samples is $50 \mathrm{wt} \%$. (d) The experimental results and theoretical values before and after sintering. The insets are the SEM images before (left) and after (right) calcination. Scale bar: $5 \mu \mathrm{m}$.

and a large amount of heat release in this stage as well, which is an obvious combustion process, suggesting that the sample starts to combust from $500^{\circ} \mathrm{C}$ until the end of $600^{\circ} \mathrm{C}$, losing about $14 \%$ of its mass. Combining the STA, $\mathrm{XRD}$ and FTIR results, the calcination procedure was determined consisting a heat ramp of $5^{\circ} \mathrm{C} \mathrm{min}^{-1}$ from ambient temperature to $140^{\circ} \mathrm{C}, 260$ to $500^{\circ} \mathrm{C}$, and a heat ramp of $0.5^{\circ} \mathrm{C} \mathrm{min}^{-1}$ from 140 to $260^{\circ} \mathrm{C}, 500$ to $600^{\circ} \mathrm{C}$, respectively. It is expected to maintain the structures as a result of slowing down the reaction rate including evaporation and combustion. When the temperature reaches $600^{\circ} \mathrm{C}$, a dwell time of $3 \mathrm{~h}$ is set for better crystallization.

The XRD patterns suggest a single phase of tetragonal $\mathrm{SnO}_{2}$. The XRD result shows that under the calcinaton condition of $600^{\circ} \mathrm{C}$, the organic components almost disappear, and the crystallized $\mathrm{SnO}_{2}$ nanoparticles can be formed successfully. The characteristic peaks of FTIR spectra at about 549 and $600 \mathrm{~cm}^{-1}$ are ascribed to the metal-oxygen bonding ( $\mathrm{Sn}-\mathrm{O}$ ) modes (Fig. 3c). With the increase of temperature, the characteristic peak intensities in the XRD patterns and FTIR spectra of the sample increase, revealing that the crystallinity of $\mathrm{SnO}_{2}$ increases. As shown in Fig. 3d, before and after sintering, the actual measurement results are in accordance with the theore- tical value using Equation (4) fitting, and the ratio of shrinkage is about $80.6 \%-88.7 \%$. The remaining data are presented in Figs S1 and S2. With different mass ratios of $\mathrm{SnCl}_{4} \cdot 5 \mathrm{H}_{2} \mathrm{O}$, the feature shrinkage of the structures is illustrated in Fig. S3. The concept of a pegasus-like sculpture before and after calcination is demonstrated in Fig. 4a, b. SEM images of other 3D microstructures before and after calcination are displayed in Fig. S4. It should be noted that there is some deformation at the bottom of the structures, because the bottom section is firmly adhered to the silicon substrate and calcinated under the constraint conditions, while the top section keeps nearly isotropically uniform shrinking.

\section{Microstructure and chemical composition of the $\mathrm{SnO}_{2}$ ceramic structures}

After focused ion beam (FIB) cutting, the calcinated sample was prepared, and a thin slice is displayed in Fig. 4g. The high-angle annular dark field (HAADF) reveals that the calcined $\mathrm{SnO}_{2}$ is nearly fully dense and nanocrystalized, with an average crystalline grain size of $2.5 \pm 0.4 \mathrm{~nm}$. And the elemental distribution is proved by the energy dispersive spectrometer (EDS), giving information that the $\mathrm{O}$ and $\mathrm{Sn}$ atoms are uniformly dis- 
a

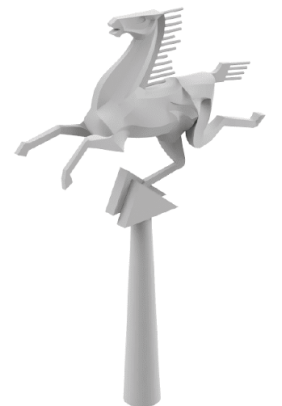

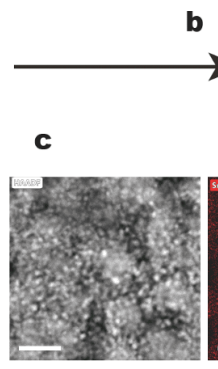

b

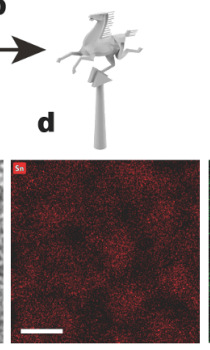

g
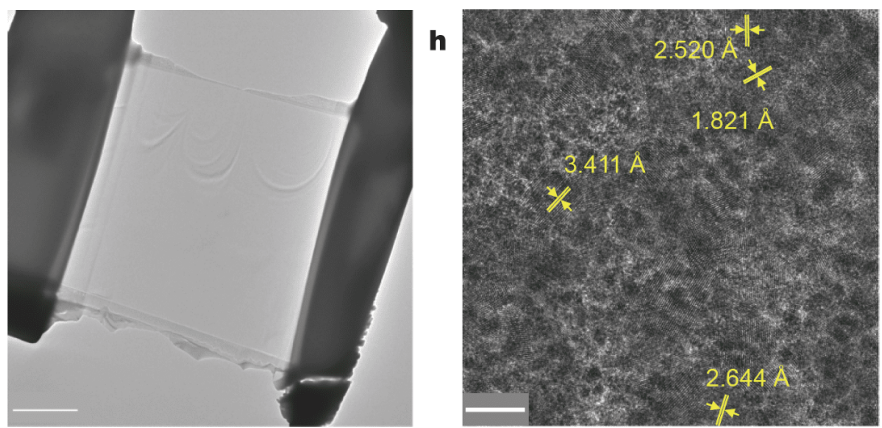
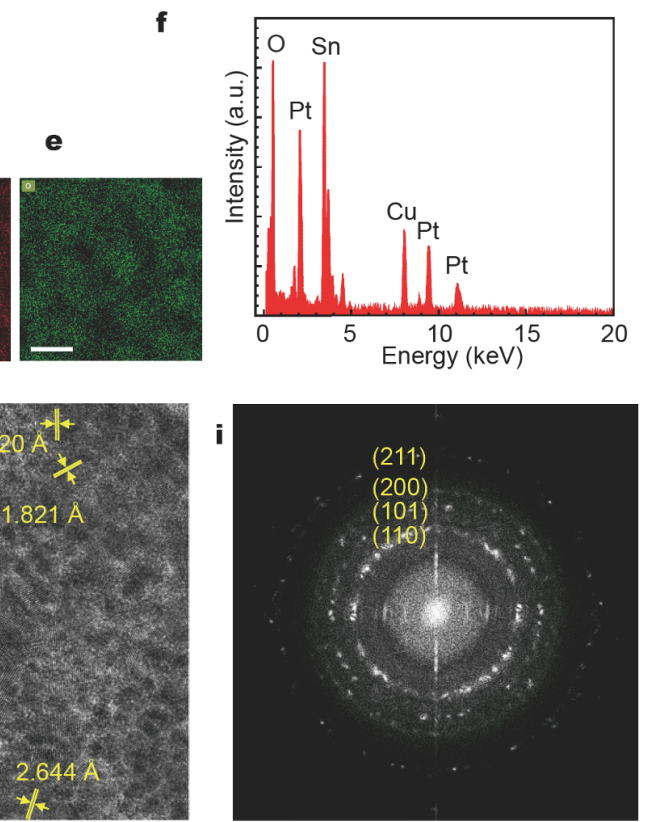

Figure 4 The illustration of a pegasus-like sculpture (a) before and (b) after the calcination treatment. (c) Scanning TEM image of a calcinated structure and the EDS mapping of (d) tin and (e) oxygen. (f) EDS spectrum. (g) TEM sample created with FIB and micromanipulator. (h) HRTEM image of a calcinated structure. (i) The analysis of interplanar distances using FFT. Scale bars are $20 \mathrm{~nm}$ for (c-e), $2 \mu \mathrm{m} \mathrm{for} \mathrm{(g),} \mathrm{and} 10 \mathrm{~nm}$ for (h).

tributed throughout the structure (Fig. 4c-f). The Pt and $\mathrm{Cu}$ elements come from the Pt sputtered during FIB cutting and the copper coils in the TEM, respectively. By combining the HRTEM image with the fast Fourier transform (FFT) image (Fig. 4h, i), it can be confirmed that the four distinct lattice spacings of $1.821,2.520$, 2.644, and $3.411 \AA$ correspond to the interplanar distances of tetragonal $\mathrm{SnO}_{2}$ (211), (200), (101), and (110) planes, respectively. Nanocrystalized $\mathrm{SnO}_{2}$ ceramic nanostructures are formed via this technique.

\section{CONCLUSIONS}

An approach with high resolution to manufacture 3D $\mathrm{SnO}_{2}$ ceramic nanostructures was developed. Through this process, $\mathrm{SnO}_{2}$ could be fabricated into arbitrary nanostructures without complex chemical synthesis. By tuning the concentration of $\mathrm{SnCl}_{4} \cdot 5 \mathrm{H}_{2} \mathrm{O}$, the polymerization threshold can be adjusted, and the feature size of the fabricated structures can be controlled by varying the laser exposure conditions. Through the control of the pyrolysis process, a uniform shrinkage of the structure can be achieved. This work provides the possibility of manufacturing $3 \mathrm{D} \mathrm{SnO}_{2}$ ceramic structures with submicrometer resolution. Considering the excellent property of $\mathrm{SnO}_{2}$, it opens a new door for catalysis and electrochemical performance engineering via geometrical structure tuning, thus offering a new freedom for material property design.

Received 24 June 2020; accepted 16 October 2020; published online 4 January 2021

1 Maduraiveeran G, Sasidharan M, Jin W. Earth-abundant transition metal and metal oxide nanomaterials: Synthesis and electrochemical applications. Prog Mater Sci, 2019, 106: 100574

2 Yarali E, Koutsiaki C, Faber H, et al. Recent progress in photonic processing of metal-oxide transistors. Adv Funct Mater, 2020, 30: 1906022

3 Ren Y, Zou Y, Liu Y, et al. Synthesis of orthogonally assembled 3D cross-stacked metal oxide semiconducting nanowires. Nat Mater, 2020, 19: 203-211

4 Kim R, Jang JS, Kim DH, et al. A general synthesis of crumpled metal oxide nanosheets as superior chemiresistive sensing layers. Adv Funct Mater, 2019, 29: 1903128

5 Lan $\mathrm{K}$, Wang $\mathrm{R}$, Zhang $\mathrm{W}$, et al. Mesoporous $\mathrm{TiO}_{2}$ microspheres with precisely controlled crystallites and architectures. Chem, 2018, 4: 2436-2450

6 Bauer J, Meza LR, Schaedler TA, et al. Nanolattices: An emerging class of mechanical metamaterials. Adv Mater, 2017, 29: 1701850

7 Yang J, Li Z, Xin X, et al. Designing electromechanical metamaterial with full nonzero piezoelectric coefficients. Sci Adv, 2019, 5: eaax 1782

8 Berger JB, Wadley HNG, McMeeking RM. Mechanical metamaterials at the theoretical limit of isotropic elastic stiffness. Nature, 2017, 543: 533-537

9 Feng L, Huo P, Liang Y, et al. Photonic metamaterial absorbers: Morphology engineering and interdisciplinary applications. Adv 
Mater, 2019, 1903787

10 Choe HS, Prabhakar R, Wehmeyer G, et al. Ion write microthermotics: Programing thermal metamaterials at the microscale. Nano Lett, 2019, 19: 3830-3837

11 Zheng X, Smith W, Jackson J, et al. Multiscale metallic metamaterials. Nat Mater, 2016, 15: 1100-1106

12 Zhu C, Han TYJ, Duoss EB, et al. Highly compressible 3D periodic graphene aerogel microlattices. Nat Commun, 2015, 6: 6962

13 Eckel ZC, Zhou C, Martin JH, et al. Additive manufacturing of polymer-derived ceramics. Science, 2016, 351: 58-62

14 Travitzky N, Bonet A, Dermeik B, et al. Additive manufacturing of ceramic-based materials. Adv Eng Mater, 2014, 16: 729-754

15 Zhang $\mathrm{W}$, Xiao X, Zhang $\mathrm{Y}$, et al. In situ synthesized $\mathrm{SnO}_{2}$ nanorod/reduced graphene oxide low-dimensional structure for enhanced lithium storage. Nanotechnology, 2018, 29: 105705

16 Jiang Q, Zhang X, You J. $\mathrm{SnO}_{2}$ : A wonderful electron transport layer for perovskite solar cells. Small, 2018, 14: 1801154

$17 \mathrm{Wu} \mathrm{N}, \mathrm{Du} \mathrm{W}, \mathrm{Gao} \mathrm{X}$, et al. Hollow $\mathrm{SnO}_{2}$ nanospheres with oxygen vacancies entrapped by a $\mathrm{N}$-doped graphene network as robust anode materials for lithium-ion batteries. Nanoscale, 2018, 10: $11460-11466$

18 Schaedler TA, Jacobsen AJ, Torrents A, et al. Ultralight metallic microlattices. Science, 2011, 334: 962-965

19 Zhang YL, Chen QD, Xia H, et al. Designable 3D nanofabrication by femtosecond laser direct writing. Nano Today, 2010, 5: 435-448

20 Zhang X, Yao J, Liu B, et al. Three-dimensional high-entropy alloypolymer composite nanolattices that overcome the strengthrecoverability trade-off. Nano Lett, 2018, 18: 4247-4256

21 Wang X, Nie Z, Liang Y, et al. Recent advances on optical vortex generation. Nanophotonics, 2018, 7: 1533-1556

22 Wang X, Kuchmizhak AA, Brasselet E, et al. Dielectric geometric phase optical elements fabricated by femtosecond direct laser writing in photoresists. Appl Phys Lett, 2017, 110: 181101

23 Passinger S, Saifullah M , Reinhardt C, et al. Direct 3D patterning of $\mathrm{TiO}_{2}$ using femtosecond laser pulses. Adv Mater, 2007, 19: 1218-1221

24 Yee DW, Lifson ML, Edwards BW, et al. Additive manufacturing of 3D-architected multifunctional metal oxides. Adv Mater, 2019, 31: 1901345

25 Vyatskikh A, Delalande S, Kudo A, et al. Additive manufacturing of 3D nano-architected metals. Nat Commun, 2018, 9: 593

26 Gailevičius D, Padolskytè V, Mikoliūnaite L, et al. Additive-manufacturing of $3 \mathrm{D}$ glass-ceramics down to nanoscale resolution. Nanoscale Horiz, 2019, 4: 647-651

27 Masteghin MG, Varela JA, Orlandi MO. Controlling the breakdown electric field in $\mathrm{SnO}_{2}$ based varistors by the insertion of $\mathrm{SnO}_{2}$ nanobelts. J Eur Ceramic Soc, 2017, 37: 1535-1540

28 Liang J, Yuan C, $\mathrm{Li} \mathrm{H}$, et al. Growth of $\mathrm{SnO}_{2}$ nanoflowers on Ndoped carbon nanofibers as anode for $\mathrm{Li}$ - and $\mathrm{Na}$-ion batteries. Nano-Micro Lett, 2018, 10: 21

29 Yin XT, Zhou WD, Li J, et al. Tin dioxide nanoparticles with high sensitivity and selectivity for gas sensors at sub-ppm level of hydrogen gas detection. J Mater Sci-Mater Electron, 2019, 30: 1468714694

30 Zhou X, Hou Y, Lin J. A review on the processing accuracy of twophoton polymerization. AIP Adv, 2015, 5: 030701

31 Serbin J, Egbert A, Ostendorf A, et al. Femtosecond laser-induced two-photon polymerization of inorganic-organic hybrid materials for applications in photonics. Opt Lett, 2003, 28: 301-303

32 Cardenas-Benitez B, Eschenbaum C, Mager D, et al. Pyrolysis- induced shrinking of three-dimensional structures fabricated by two-photon polymerization: Experiment and theoretical model. Microsyst Nanoeng, 2019, 5: 38

Acknowledgements This work was supported by Foshan Xianhu Laboratory of the Advanced Energy Science and Technology Guangdong Laboratory (XHT2020-003 and XHT2020-005), the Fundamental Research Funds for the Central Universities (2020IVA068), the Creative Research Group Project of Natural Science Foundation of China (61821003), and the National Natural Science Foundation of China (61775068 and 51802239).

Author contributions Cheng $\mathrm{Y}$ and Mai L were in charge of this scientific research project; Wang $\mathrm{X}$ and Gan $\mathrm{Z}$ finalized the manuscript; Chai $\mathrm{N}$ and Liu $\mathrm{Y}$ conducted most of the experiments and data analyses together as well as wrote the manuscript; Zhang Q and Huang F contributed to the photoresit preparation and analysis; Zeng $\mathrm{Z}$ and Wei $\mathrm{P}$ performed the HRTEM analysis and helped discuss and revise the manuscript; Yue Y and Zhao J performed the pyrolysis experiments and contributed to revising the manuscript. The manuscript was written through contributions of all authors. All authors have given approval to the final version of the manuscript.

Conflict of interest The authors declare that they have no conflict of interest.

Supplementary information online version of the paper.

Supporting data are available in the

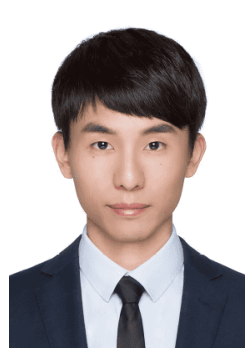

Nianyao Chai received his BS degree in 2018 from Wuhan University of Technology (WUT). $\mathrm{He}$ is currently a $\mathrm{PhD}$ candidate at WUT. His current research interest is focused on the field of ultrafast laser 3D nonlinear photolithography.

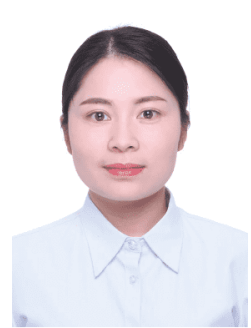

Yanan Liu received her Master degree in 2017 from Hebei University in China, and is currently a $\mathrm{PhD}$ candidate at Huazhong University of Science and Technology. Her research direction is laser direct writing crystallization technology of optical materials.

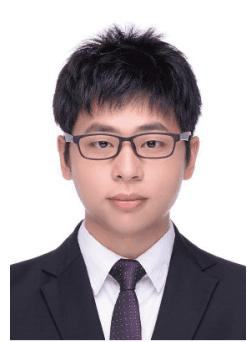

Xuewen Wang obtained his $\mathrm{PhD}$ degree in 2017 from Swinburne University of Technology, and joined WUT in 2019, and acted as the deputy director of the Femtosecond Laser Manufacturing Center for Advanced Materials and Devices. His research interests include the ultrafast lasermatter interactions, laser-derived nanomaterial synthesis and modification, ceramic nanostructuring, and nonlinear photolithography. 


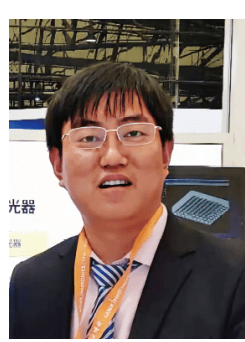

Zongsong Gan received his BS degree in 2008 from Nankai University, China, and $\mathrm{PhD}$ degree in 2013 from Swinburne University of Technology, Australia. Now he is a professor of Wuhan Optoelectronics National Research Center, Huazhong University of Science and Technology. His research direction is the development of new principle lithography machine technology and new photoresist materials.

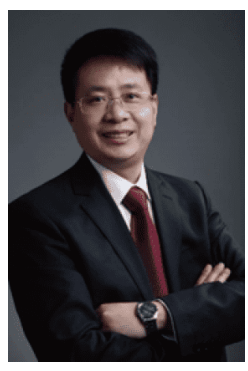

Liqiang Mai, Chair Professor of Materials Science and Engineering at WUT, Dean of School of Materials Science and Engineering at WUT, Fellow of the Royal Society of Chemistry. He received his $\mathrm{PhD}$ degree in 2004 from WUT and carried out his postdoctoral research at Georgia Institute of Technology in 2006-2007. $\mathrm{He}$ worked as an advanced research scholar at Harvard University and the University of California, Berkeley. His current research interests focus on new nanomaterials for electrochemical energy storage and micro/nano energy devices.

\section{氧化锡陶瓷的飞秒激光3D非线性光刻}

柴年圭 ${ }^{1,2 \dagger}$, 刘亚男 ${ }^{3 \dagger}$, 岳云帆 ${ }^{1}$, 魏平 ${ }^{1}$, 王学文 ${ }^{1,2^{*}}$, 赵俊态 ${ }^{1}$, 张奇 $^{1}$, 黄福志 ${ }^{1}$, 曾终乐 ${ }^{1}$, 甘棕松 ${ }^{3^{*}}$, 麦立强 ${ }^{1,2^{*}}$, 程一兵 ${ }^{1,2}$

摘要 氧化锡是一种宽带隙半导体材料, 广泛用于气体传感、光电 和催化等领域. 微米级至纳米级的复杂三维几何结构使传统的氧 化锡陶瓷具有新的特性和功能. 由于具有高的机械㓞性和强度, 陶 瓷不易铸造或加工. 增材制造为陶瓷材料灵活的几何造型带来了 巨大的机会, 但是极高的熔化温度使其在普通的3D打印方法上更 加困难, 而在微米或纳米尺度任意成形氧化锡陶瓷始终是一个挑 战. 本文中, 我们利用在超快激光辐照下聚合的陶瓷前驱体, 形成 复杂且任意的 $3 \mathrm{D}$ 陶瓷聚合物结构, 通过烧烧处理后转变为具有均 匀收缩率的高密度纯氧化锡陶瓷, 特征尺寸可降至亚微米. 透射电 子显微镜(TEM) 分析显示, 氧化锡陶瓷纳米晶体的晶粒尺寸为 $2.5 \pm$ $0.4 \mathrm{~nm}$. 这项工作为制造精度高达亚百纳米的任意 $3 \mathrm{D}$ 氧化锡陶瓷 纳米结构提供了可能性, 从而使其在不同领域更具应用前景. 